\title{
Process of LoAD Balancing IN Cloud COMPUTING USING GENETIC ALGORITHM
}

\author{
Md. Shahjahan Kabir ${ }^{1}$, Kh. Mohaimenul Kabir ${ }^{2}$ and Dr. Rabiul Islam ${ }^{3}$ \\ ${ }^{1}$ Dept. of CSE, Dhaka International University, Dhaka, Bangladesh \\ ${ }^{2}$ Dept. of CSE, Dhaka International University, Dhaka, Bangladesh \\ ${ }^{3}$ Associate Professor, Dept. of CSE, RUET, Rajshahi, Bangladesh
}

\begin{abstract}
The running generation of world, cloud computing has become the most powerful, chief and also lightning technology. IT based companies has already changed their way to buy and design hardware through this technology. It is a high utility which can also make software more attractive. Load balancing research in cloud technology is one of the burning technologies in modern time. In this paper, pointing various proposed algorithms, the topic of load balancing in Cloud Computing are researched and compared to provide a gist of the latest way in this research area. By using Genetic Algorithm the balance is most flexible which is represented here.
\end{abstract}

\section{KEYWORDS}

Genetic Algorithm, Load balancing, Cloud Computing.

\section{INTRODUCTION}

The latest vision of large distributed computing is "Cloud". Cloud based multimedia system (CMS) gained momentum as there is large number of users. Cloud computing is internet based computing, whereby shared resources, software and information are provided to computers and other devices on-demand, like a public utility. [1] Recent the most burning topic is Cloud storage for the IT user. Because when a user uses a personal or professional computer for a great purpose, then they must have some precious files, for which that man is ready to invest more invest to protect the file. As the scope of cloud scales up, cloud computing service suppliers needs handling of gigantic requests. The principal challenge converts to keep the performance same or better whenever such an outbreak happens. Thus in spite of glorious future of Cloud Computing, many actual problems still essential to be explored for its perfect awareness. One of these concerns is Load balancing. [2] The following network resources can be load balanced:

- Network edges and facilities such as DNS,FTP, and HTTP

- Making Connections through intelligent switches

- Processing through computer system task

- Storage resources right of entry to application instances.

Without balancing load it is too much hard to manage this cloud computing. As a soft computing approach Genetic Algorithm has been used in this paper. Cloud Analyst - A Cloud Sims built Visual Modeler has been used for simulation and analysis of the algorithm. The performance of DOI : $10.14810 /$ ecij.2015.4206 
Genetic Algorithm is related with two commonly used scheduling algorithm FCFS and RR and a local search algorithm stochastic hill climbing. [3] The GA operates on a pool of chromosomes which denote candidate results to the problem. Chromosomes are selected following "survival of the fittest" and are approved on to the next generation in a development called "reproduction". An objective function is supplied and used to weigh the relative facts (the so-called "fitness value") of the chromosomes in the pool, and the reproduction is understood by the genetic operators, such as selection, crossover and mutation, to generate new points in the search space. [4] Genetic Algorithm system performs better than greedy heuristic system. This algorithm is also suitable for the load balancing system. But there is some trouble too such as the GA is quite complicated and time consuming. But time can be reduced through the proposed method. Due to the best balancing proposed system performs so much highly and perfectly in cloud network.

\section{DESCRIPTION OF CLOUD SYSTEM, LOAD BALANCING \& GENETIC ALGORITHM}

\subsection{Cloud System}

Mainly, cloud computing means storing and accessing data and programs over the internet as an alternative of the computer's hard drive. The cloud is just a comparison for the Internet. It goes back to the days of flowcharts and presentations that would represent the gigantic server-farm infrastructure of the Internet as unknown but a puffy, white cumulonimbus cloud, accepting connections and doling out info as it floats.

Cloud computing characterizes a real model shift in the way in which systems are arranged. The gigantic scale of cloud computing organizations was enabled by the popularization of the Internet and the enlargement of some large service companies. Cloud computing makes the long-held dream of utility computing possible with a pay-as-you-go, infinitely scalable, universally available system. With cloud computing, anybody can start very small and become big very fast. That's why cloud computing is radical, even if the technology it is constructed on is evolutionary. [6]

\subsection{Scheduling Server for Load balancing}

Load Balancing is firstly distributed by cost. Because Cloud computing is costly. When someone pays, then the scheduling System gives high priority to the most paid user. 


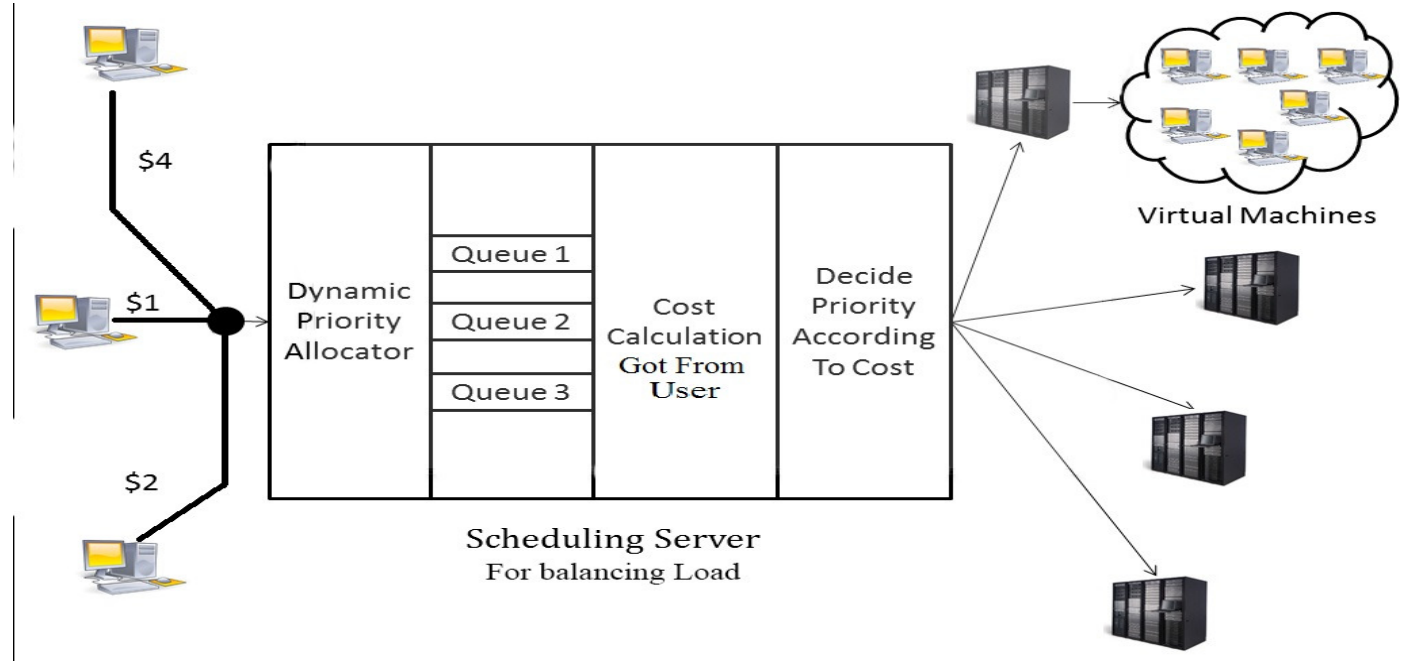

Figure 1. Scheduling server for balancing load in cloud computing.

Then it gives importance to $2^{\text {nd }}$ maximum paid user. That means who pays low cost, his file distributes with low priority. In the Figure 1, this is labeled that the priority for $\$ 4$ is more than $\$ 2$ and $\$ 2$ is more earlier than $\$ 1$. This is called the scheduling in cloud computing.

\subsection{Genetic Algorithm \& Equation}

The load balancing abides by three rules such as the location rule, the distribution rule, and the selection rule. Here the work will process through a dynamic process after doing scheduling server. Firstly the tasks will be fixed a number. Afterward it will auto execute task number and size randomly. Then the task handled from a task slot, where the randomly generator are deposited for processed.

Mainly the development of cloud computing is dynamic but for the arrangement purpose it can be expressed as allocating $\mathrm{N}$ number of jobs applied by the cloud customers to $\mathrm{M}$ number of processing unit in cloud. Every processing unit has a processing unit vector (PUV), where vector consists of MIPMS that mean how many million instructions can be processed by the machine per second. $\mathrm{R}$ is indicated as delay cost and $\mathrm{x}$ is cost of execution of instruction. If these indicated, the equation will be as below.

$P U V=f(M I P M S, \mathrm{x}, R)$

Same formula for each job submitted by the cloud user can be defined by job unit vector (JUV), Which is characterized by $\mathrm{JUV}=\mathrm{f}(\mathrm{t}, \mathrm{NIC}, \mathrm{AT}, \mathrm{wc})$

Here $t$ defines the types of the jobs, Software as a Service (SAAS), Infrastructure as a Service (IAAS) and Platform-as-a-Service (PAAS). NIC represents the number of instruction which is present. After this term costing is calculated for $\mathrm{N}$ jobs among $\mathrm{M}$ number of processors representing in equation (iii).

$\zeta=W 1 * \mathrm{x}(N I C \div M I P M S)+W 2 * R$

In the equation (iii) $\mathrm{W} 1$ and $\mathrm{W} 2$ are weights. It is very problematic to decide or optimize the weights, one criterion could be that the factor is larger is the weight. The Logic is that cloud users preference or importance of user given to a certain factor over the other. The weight are defined as $\mathrm{W} 1=0.8$ and $\mathrm{W} 2=0.2$ that means the sum is 1 . So the load balancing is hard to do. Because the mechanism of a simple GA are amazingly simple, involving nothing more complex than copying strings and exchange partial strings. Simplicity of action and power of effect are two main 
Electrical \& Computer Engineering: An International Journal (ECIJ) Volume 4, Number 2, June 2015

magnetisms of the GA approach. The efficiency of the GA depends upon an suitable mix of exploration and exploitation. Three operators to achieve this are: selection, crossover, and mutation. [4] So this paper is going to reduce the problem of balancing load with simplifying the GA in the section of cloud computing. Genetic Algorithm mainly works with genesis, crossover and mutation. The progress of working method of GA is shown in the Figure 2.

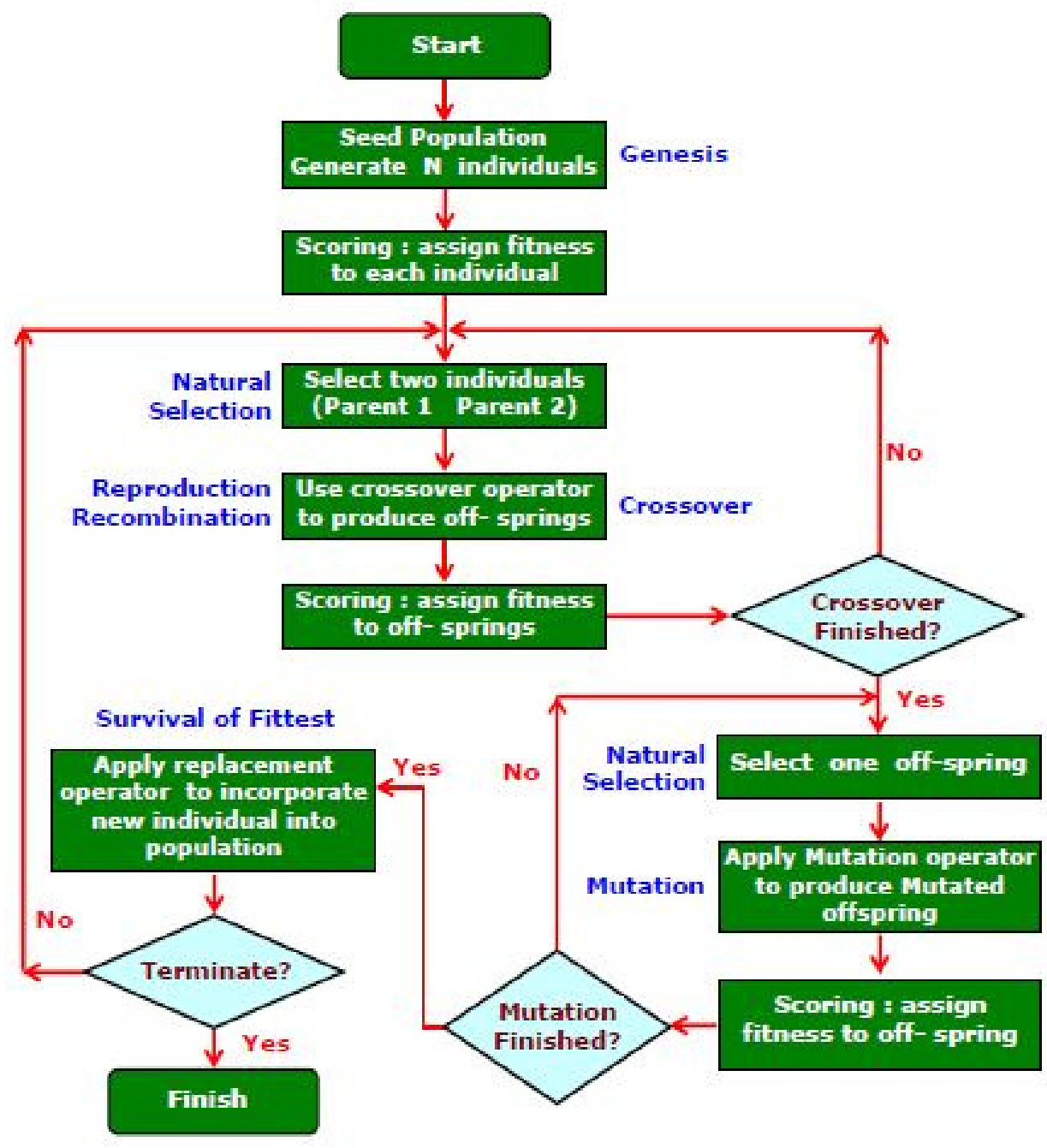

Figure 2. The flow chart of Genetic Algorithm

\section{PROPOSED ALGORITHM}

A method with GA is simplified by three operations. Where it can be justified the load balance, these are selection, operation and replacement. Processor mainly processes the balance through as below Figure 3. 
Electrical \& Computer Engineering: An International Journal (ECIJ) Volume 4, Number 2, June 2015

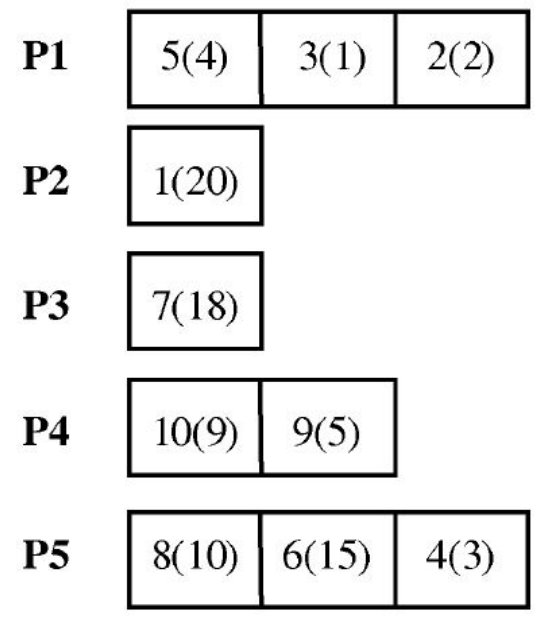

Figure 3. Load balancing through processor.

Where P1, P2 balancing technique is given below.

P5 are the number of processors. The proposed

Step 1: At the starting point, randomly initialize a population of processing unit after coding them into binary strings.

Step 2: Calculate the main value of each population for the fitness part.

Step 3: If the maximum number of iteration or optimum solution is found then do:

Step 3(a): Consider chromosome with lowest fitness twice and delete the chromosome with maximum fitness value to build the mating pool.

Step 3(b): Use single point crossover by randomly picking the crossover point to make new offspring.

Step 3(c): With a mutation probability of (0.05), mutate new offspring.

Step 3(d): As new population place new offspring and use this population for following round of iteration. This is called the accepting part.

Step 3(e): Finally test for the end condition.

Step 4: End.

\section{EXECUTION}

After performed the basic operation that means when fitness calculation, selection implementation, crossover operation and mutation operation are completed then the execution will end and the results found. In GA, the population initialization is well-thought-out to be the preprocessing hence its thickness is not considered for review. For programming into binary string a time density of at maximum $\mathrm{n} 1$, for estimation of cost function 3 it is at maximum $(\mathrm{c} \times \mathrm{k})$ for testing cost $\mathrm{c}$ of $\mathrm{k}$ number of chromosomes. Selection process has a time complexity of at most $\mathrm{m}$, for single point crossover the time complexity is at most $\mathrm{m}$, where $\mathrm{m}$ is chromosome 
Electrical \& Computer Engineering: An International Journal (ECIJ) Volume 4, Number 2, June 2015

length and for mutation at any place it is again $\mathrm{m}$. The three action of GA are frequent iteratively till the discontinuing norms is met so the total time complexity $\mathrm{G}$ is given by equation (iv),

$\mathrm{G}=\mathrm{O}\{\mathrm{n} 1+(\mathrm{c} \times \mathrm{k})+(\mathrm{n} 2+1)(\mathrm{m}+\mathrm{m}+\mathrm{m})\}$

For more smooth working the equation can be more effective in this case.

\subsection{Results Using One Data Centre}

Table 1: Calculation of total average response rate in milliseconds \& Model setup

\begin{tabular}{|c|c|c|c|c|c|}
\hline $\begin{array}{c}\text { Formation } \\
\text { of Cloud }\end{array}$ & $\begin{array}{c}\text { 1 DC } \\
\text { With No. } \\
\text { of VMs }\end{array}$ & $\begin{array}{c}\text { RR } \\
\text { Response } \\
\text { time }\end{array}$ & $\begin{array}{c}\text { SHC } \\
\text { Response } \\
\text { time }\end{array}$ & $\begin{array}{c}\text { FCFS } \\
\text { response } \\
\text { time }\end{array}$ & $\begin{array}{c}\text { GA Response } \\
\text { time }\end{array}$ \\
\hline FC1 & 30 & 330.50 & 330.24 & 330.84 & 320.03 \\
\hline FC2 & 60 & 330.20 & 329.64 & 331.07 & 330.88 \\
\hline FC3 & 90 & 331.01 & 329.94 & 329.98 & 323.66 \\
\hline FC4 & 120 & 329.84 & 329.55 & 330.02 & 324.21 \\
\hline
\end{tabular}

\subsection{Results Using Two Data Centre}

Table 2: Model Setup \& Calculation of total response rate in milliseconds

\begin{tabular}{|c|c|c|c|c|c|}
\hline $\begin{array}{c}\text { Formation } \\
\text { of Cloud }\end{array}$ & $\begin{array}{c}\text { 2 DCs } \\
\text { With No. of } \\
\text { VMs }\end{array}$ & $\begin{array}{c}\text { RR } \\
\text { Response } \\
\text { time }\end{array}$ & $\begin{array}{c}\text { SHC } \\
\text { Response } \\
\text { time }\end{array}$ & $\begin{array}{c}\text { FCFS } \\
\text { response } \\
\text { time }\end{array}$ & $\begin{array}{c}\text { GA Response } \\
\text { time }\end{array}$ \\
\hline FC1 & 30 & 373.22 & 371.17 & 382.42 & 364.31 \\
\hline FC2 & 60 & 371.13 & 368.42 & 382.11 & 363.68 \\
\hline FC3 & 90 & 370.01 & 369.51 & 385.98 & 363.65 \\
\hline FC4 & 120 & 370.07 & 368.11 & 381.78 & 364.26 \\
\hline FC5 & 30,60 & 371.03 & 369.32 & 380.20 & 363.22 \\
\hline FC6 & 30,90 & 372.02 & 368.11 & 380.19 & 364.23 \\
\hline FC7 & 30,120 & 372.33 & 367.45 & 379.56 & 363.45 \\
\hline FC8 & 60,90 & 371.11 & 369.55 & 378.65 & 363.77 \\
\hline FC9 & 60,120 & 370.27 & 367.22 & 379.88 & 361.77 \\
\hline FC10 & 90,120 & 369.92 & 368.88 & 377.02 & 360.02 \\
\hline
\end{tabular}


Electrical \& Computer Engineering: An International Journal (ECIJ) Volume 4, Number 2, June 2015

\subsection{Results Using Three Data Centre}

Table 3: Model Setup \& Calculation of total response rate in milliseconds

\begin{tabular}{|c|c|c|c|c|c|}
\hline $\begin{array}{c}\text { Formation } \\
\text { of Cloud }\end{array}$ & $\begin{array}{c}\text { DC With } \\
\text { No. of VMs }\end{array}$ & $\begin{array}{c}\text { RR } \\
\text { Response } \\
\text { time }\end{array}$ & $\begin{array}{c}\text { SHC } \\
\text { Response } \\
\text { time }\end{array}$ & $\begin{array}{c}\text { FCFS } \\
\text { response } \\
\text { time }\end{array}$ & $\begin{array}{c}\text { GA Response } \\
\text { time }\end{array}$ \\
\hline FC1 & 30 & 340.40 & 345.51 & 339.96 & 339.03 \\
\hline FC2 & 60 & 342.21 & 342.78 & 349.18 & 338.54 \\
\hline FC3 & 90 & 339.13 & 343.82 & 348.12 & 333.45 \\
\hline FC4 & 120 & 337.45 & 342.96 & 352.02 & 333.11 \\
\hline FC5 & $\begin{array}{c}30,60,90,12 \\
0\end{array}$ & 335.22 & 339.11 & 341.18 & 331.11 \\
\hline
\end{tabular}

\subsection{Results Using Four Data Centre}

Table 4: Model Setup \& Calculation of total response rate in milliseconds

\begin{tabular}{|c|c|c|c|c|c|}
\hline $\begin{array}{c}\text { Formation } \\
\text { of Cloud }\end{array}$ & $\begin{array}{c}\text { DC With } \\
\text { No. of } \\
\text { VMs }\end{array}$ & $\begin{array}{c}\text { RR } \\
\text { Response } \\
\text { time }\end{array}$ & $\begin{array}{c}\text { SHC } \\
\text { Response } \\
\text { time }\end{array}$ & $\begin{array}{c}\text { FCFS } \\
\text { Response } \\
\text { time }\end{array}$ & $\begin{array}{c}\text { GA Response } \\
\text { time }\end{array}$ \\
\hline FC1 & 30 & 333.77 & 346.42 & 342.45 & 333.38 \\
\hline FC2 & 60 & 334.88 & 345.64 & 341.65 & 329.76 \\
\hline FC3 & 90 & 337.76 & 342.17 & 343.78 & 327.66 \\
\hline FC4 & 120 & 336.91 & 341.88 & 341.76 & 323.11 \\
\hline FC4 & $\begin{array}{c}30,60,90, \\
120\end{array}$ & 335.84 & 341.59 & 340.28 & 321.77 \\
\hline
\end{tabular}


Electrical \& Computer Engineering: An International Journal (ECIJ) Volume 4, Number 2, June 2015

\subsection{Results Using Five Data Centre}

Table 5: Model Setup \& Calculation of total response rate in milliseconds

\begin{tabular}{|c|c|c|c|c|c|}
\hline $\begin{array}{c}\text { Formation } \\
\text { of Cloud }\end{array}$ & $\begin{array}{c}\text { DC With } \\
\text { No. of } \\
\text { VMs }\end{array}$ & $\begin{array}{c}\text { RR } \\
\text { Response time }\end{array}$ & $\begin{array}{c}\text { SHC } \\
\text { Response time }\end{array}$ & $\begin{array}{c}\text { FCFS } \\
\text { Response time }\end{array}$ & $\begin{array}{c}\text { GA Response } \\
\text { time }\end{array}$ \\
\hline FC1 & 30 & 330.16 & 340.76 & 339.73 & 321.30 \\
\hline FC2 & 60 & 331.62 & 339.38 & 338.37 & 318.03 \\
\hline FC3 & 90 & 337.56 & 338.49 & 336.58 & 317.01 \\
\hline FC4 & 120 & 335.98 & 339.91 & 335.76 & 316.88 \\
\hline FC4 & $\begin{array}{c}30,60,90,1 \\
20\end{array}$ & 331.99 & 337.37 & 331.59 & 315.01 \\
\hline
\end{tabular}

\section{Conclusions}

From the graph shown above it can be conclude that the proposed system is better for the latest technology. This paper can do better load balancing with the help of Genetic Algorithm in the cloud network.

\section{REFERENCES}

[1] Manisha B. Jadhav, Vishnu J. Gaikwad, C. V. Patil, G. S. Deshpande,2010. CLOUD COMPUTING APPLICATIONS IN COMPUTATIONAL SCIENCE, International Journal of Advanced Computer and Mathematical Sciences.. Vol 1, Issue 1. Pp. 1-6.

[2] A Genetic Algorithm (GA) based Load Balancing Strategy for Cloud Computing, Kousik Dasguptaa, Brototi Mandalb, Paramartha Duttac, Jyotsna Kumar Mondald, Santanu Dame ,International Conference on Computational Intelligence: Modeling Techniques and Applications (CIMTA), Procedia Technology 10 ( 2013 ) Pp. 340 - 347.

[3] M. D. Dikaiakos, G. Pallis, D. Katsa, P. Mehra, and A. Vakali, "Cloud Computing: Distributed Internet Computing for IT and Scientific Research", in Proc. of IEEE Journal of Internet Computing, Vol. 13, No. 5, pp. 10-13, 2009.

[4] On File and Task Placements and Dynamic Load Balancing in Distributed Systems, Po-Jen Chuang and Chi-Wei Cheng, Tamkang Journal of Science and Engineering, Vol. 5, No. 4, pp. 241-252 (2002).

[5] Observations on Using Genetic Algorithms for Dynamic Load-Balancing Albert Y. Zomaya, Senior Member, IEEE, and Yee-Hwei IEEE Transactions on Parallel and Distributed Systems, Vol. 12, No. 9, September 2001.

[6] Cloud Computing Bible book, Barrie Sisisky, ISBN: 978-0-470-90356-8.

[7] Comparative Study on Load Balancing Techniques in Cloud Computing, Open Journal of Mobile Computing and Cloud Computing, N. S. Raghava* and Deepti Singh, Volume 1, Number 1, August 2014. 
Electrical \& Computer Engineering: An International Journal (ECIJ) Volume 4, Number 2, June 2015

\section{AUTHORS}

Md. Shahjahan Kabir is currently a lecturer of CSE in Dhaka International University. He has got Bsc. from RUET in 2012. He has already three online publications in the international journal .

Kh. Mohaimenul Kabir is a current student of Bsc. in CSE in Dhaka international University. He has a online publication in online journal.

Dr. Rabiul Islam is currently a Associate professor of CSE in RUET. He has already completed his Bsc. , Msc and Phd. From RUET. He has lots of research and publications. He has published 65 online international journals till now 